\title{
Lucrecio y el materialismo de lo imaginario
}

\author{
Lucretius and the Materialism \\ of the Imaginary \\ Aurelio Sainz Pezonaga \\ (IES Santiago Grisolía de Cuenca)
}

Recibido: 08/09/2011

Aceptado: 07/11/2012

\section{Resumen}

El texto propone una lectura de la teoría de lo imaginario de Lucrecio en la línea de un materialismo de lo imaginario afín al de Spinoza y Althusser. Este materialismo defiende que lo imaginario implica un mecanismo específico que produce un efecto específico. En Lucrecio el modo de funcionamiento específico es la obsesión por imaginarnos mirando y el efecto que deriva de él es la creencia en un alma inmortal y separable. La demostración descansa en el carácter finito de nuestro imaginario: nuestra incapacidad de representar la muerte. El argumento se desenvolverá buscando resolver el problema que el temor a morir como miedo a la ausencia de sensibilidad le presenta a la filosofía epicúrea y lucreciana, ya que este miedo no parece disiparse ante la tesis de que la muerte no es nada para nosotros. El artículo, en fin, intentará demostrar que el temor a morir y la creencia en un alma separable del cuerpo e inmortal van ligados necesariamente en todos los casos.

Palabras clave: Althusser, Spinoza, Lucrecio, Epicuro, imaginario, imaginación, materialismo, temor a la muerte, deseo de vivir, la imposibilidad de representar la muerte, la imagen que nadie mira.

\section{Abstract}

The text proposes a reading of the theory of the imaginary of Lucretius in line with a materialism of the imaginary akin to that of Spinoza and Althusser. This materialism argues that the imaginary implies a specific mechanism producing a specific effect. In Lucretius the specific operation is the obsession with imagining ourselves watching and the effect that follows from it is the belief in a separable and immortal soul. The demonstration rests on the finite nature of our imaginary: our 
inability to represent death. The argument will unfold seeking to resolve the problem presented to Epicurean and Lucretian philosophy by fear of death understood as fear of lack of sensitivity, for this fear does not seem to dissipate in front of the thesis that death is nothing to us. The article will try to demonstrate, finally, that the fear of death and the belief in an immortal soul separable from the body are necessarily linked in all cases.

Keywords: Althusser, Spinoza, Lucretius, Epicurus, imaginary, imagination, materialism, fear of death, desire to live, the impossibility of representing death, the image that nobody looks at.

[...] les grands penseurs matérialistes, qui ont compris que la liberté des hommes passait, non par la complaisance de sa reconnaissance idéologique, mais par la connaissance des lois de leur servitude, et que la 'réalisation' de leur individualité concrète passait par l'analyse et la maîtrise des rapports abstraits qui les gouvernent. (Louis Althusser, Cremonini, peintre de l'abstrait)

\section{El materialismo de lo imaginario: Spinoza y Althusser}

La afinidad entre la teoría de la imaginación de Baruj Spinoza y la teoría de la ideología de Louis Althusser fue señalada por el propio Althusser ${ }^{1}$, ha sido siempre reconocida desde entonces e incluso ha sido estudiada alguna vez ${ }^{2}$. En la línea de seguir investigando tal afinidad, proponemos aquí, como punto de partida que nos ha de llevar a la teoría de lo imaginario en Lucrecio, la tesis de que lo que caracteriza a estas teorías es que ambas defienden que la imaginación o la ideología poseen una eficacia propia. La imaginación o la ideología producen efectos específicos. En la teoría de Spinoza el efecto específico es la creencia en la libre decisión de la mente. En la de Althusser, es la transformación del individuo en sujeto.

\footnotetext{
1 Althusser, L.: "Idéologie et appareils idéologiques d'état", en Sur la reproduction, París, PUF, 1995, pp. 306 y 310n148 (trad. esp.: "Ideología y aparatos ideológicos de estado", en Posiciones, trad. A. Roies, Barcelona, Anagrama, 1977, pp. 115-6 y 121n23) y "Éléments d'autocritique", Solitude de Machiavel, París, PUF, 1998, pp. 184-5 (trad. esp.: Elementos de autocrítica, trad. M. Barroso, Laia, Barcelona, 1975, pp. 48-50). Es en este último texto donde Althusser utiliza la expresión "materialismo de lo imaginario" para referirse a la teoría de la imaginación de Spinoza.

2 Montag, W.: "The soul is the prison of the body: Althusser and Foucault, 1970-1975", Yale French Studies, 88, 1995, pp. 53-77 (trad. esp.: "El alma es la prisión del cuerpo: Althusser y Foucault, 19701975”, trad. A. Sainz Pezonaga, Youkali, 8, 2009, pp. 155-169).
} 
Sólo atendiendo a esta característica ya podemos apreciar el modo en que las teorías de Spinoza y Althusser se contraponen a las concepciones idealistas de la imaginación o de la ideología. En Aristóteles, en Descartes, en Kant, por hablar de algunas de ellas, la imaginación se mueve entre su subordinación a la sensibilidad y su dependencia del entendimiento. Y si en algún momento, o en algunas de las lecturas que el idealismo contemporáneo hace de sus clásicos, la imaginación llega a alcanzar algún grado de independencia de la una o del otro, incluso si llega a presentarse como fundamento o raíz común de ambos, lo hace a costa de tener como rasgo distintivo la pura indeterminación, esto es, la carencia de todo efecto sea del tipo que sea. De manera similar, en La ideología alemana, Marx y Engels reducen la ideología a un mero reflejo invertido de la "vida real", sin historia propia. ${ }^{3}$

Ahora bien, es evidente, que no basta con defender que la imaginación o la ideología poseen una eficacia propia, es necesario además demostrarlo. Y la manera de demostrarlo consiste, ciertamente, en exponer el automatismo específico que produce el efecto específico. Ya que el efecto específico lo es no porque se produce como hecho puntual, sino porque lo hace con una cierta necesidad que hay que explicar. En trabajos anteriores, al automatismo explicado por Spinoza lo hemos llamado "ciclo de servidumbre" 4 . El nombre que ese automatismo recibe en la teoría de Althusser es "interpelación"5.

\footnotetext{
3 Para un análisis de la imaginación en Aristóteles, véase el texto de Castoriadis, C.: "El descubrimiento de la imaginación", en Los dominios del hombre, trad. A. L. Bixio, Barcelona, Gedisa, 1998; para una comparación entre el tratamiento que hace Descartes de la imaginación y la teoría de Spinoza, véase el capítulo III, "Dynamique de l'imaginaire", del estudio de Bertrand M.: Spinoza et l'imaginaire, París, PUF, 1983; el libro clásico para las investigaciones contemporáneas en torno a la cuestión de la imaginación en Kant es, por supuesto, el de Heidegger, M.: Kant y el problema de la metafísica, trad. G. Ibscher Roth, México D.F., FCE, 1986. Sobre La ideología alemana de Karl Marx y Friedrich Engels, véase el mismo Althusser, L: "Idéologie et appareils idéologiques d'état", op. cit., pp. 294-5 (trad. esp.: "Ideología y aparatos ideológicos de estado", op. cit., pp. 100-1).

${ }^{4} \mathrm{La}$ eficacia del ciclo de servidumbre reside en que reproduce la ignorancia de las causas que nos mueven a actuar. Esto es, si la ignorancia de tales causas empieza siendo una consecuencia de la escasa potencia de nuestra mente postnatal e infantil, acaba sin embargo siendo resultado del ciclo de servidumbre. Sabido es que, según Spinoza, la creencia en la libre decisión de la mente es producida por la ignorancia de las causas que nos mueven a actuar y la conciencia de lo que deseamos. Pues bien, el ciclo de servidumbre como automatismo de la imaginación se pone en funcionamiento porque cuando nos imaginamos libres percibimos nuestra potencia de obrar sin las potencias de las otras cosas y, por tanto, con mayor distinción que si nos imaginamos determinados, esto es, si imaginamos nuestra potencia unida necesariamente a las de las otras cosas. Siendo que la mente se esfuerza en imaginar aquello que afirma su potencia de obrar (EIII, prop. 54) (no otra cosa es el amor), la mente se esfuerza por imaginarse libre, esto es, se esfuerza por reprimir cualquier explicación de las causas que la mueven a pensar y querer. Véase Sainz Pezonaga, A.: "El deseo activo de amar (afecto y materialismo en Spinoza)", Youkali, 3, mayo 2007 (www.youkali.net). Para una lectura de Spinoza que igualmente encuentra funcionando en la Ética una lógica de la recursividad, véase Bove, L.: La stratégie du conatus. Affirmation et resistance chez Spinoza, París, Vrin, 1996, cap. 6, subcap. 2 y 3 (trad. esp.: La estrategia del conatus. Afirmación y resistencia en Spinoza, trad. G. Sanz Espinar, Ciempozuelos,
} 
La afinidad entre las teorías de la imaginación y de la ideología de Spinoza y Althusser no implica, sin embargo, una identidad u homología de ningún tipo. Ambas defienden una eficacia propia de la imaginación o de la ideología y un automatismo o mecanismo que produce los efectos específicos de la creencia en la libre decisión de la mente y de la transparencia del sujeto, respectivamente. Pero las diferencias son también importantes. Aunque podrían ponerse en paralelo, la distinción de Spinoza entre la ética, lo teológico-político y lo político y la que Althusser realiza desde el materialismo histórico entre economía, ideología y política siguen siendo reparticiones muy distintas de la realidad social con efectos de sentido diferentes. Lo interesante es que esas diferencias no impiden, sino que son una condición para la formación de encuentros parciales entre ambos pensamientos, encuentros parciales que conducen de hecho a la elaboración de lecturas althusserianas de Spinoza y de lecturas spinozistas de Althusser. Nuestro propósito es, entonces, sumar a Lucrecio a este encuentro parcial entre Spinoza y Althusser y hacerlo también a través de su teoría de lo imaginario.

Tierradenadie ediciones, 2009). Es de lamentar sin embargo que Laurent Bove abandone esa lógica cuando en el capítulo siguiente (cap. 7, subcap. 1) ha de explicar el "deseo de servidumbre" y recurra, por el contrario, a una, a nuestro juicio muy discutible, supuesta necesidad vital de orden social y de código, que no de cooperación.

5 Por su parte, la interpelación es una práctica social regulada por rituales definidos por aparatos cuyo efecto específico consiste en reproducir el reconocimiento ideológico, esto es, la obviedad de la vivencia de uno mismo y de los otros como sujetos. La interpelación sólo funciona, sólo produce un sujeto transparente para sí mismo, si ese sujeto concreto existe ya de alguna manera desde siempre, esto es, si es vivida como carente de exterior. La interpelación, por tanto, no produce esa obviedad de forma ocasional, sino que sólo la puede producir a condición de reproducirla. O lo que sería decir lo mismo, la interpelación sólo funciona si reproduce el desconocimiento (méconnaissance) de sí misma como efecto y como causa dentro de un proceso socio-histórico, a saber, si reproduce el conocimiento inadecuado de la reproducción de las relaciones de producción. Véase Althusser, L.: "Idéologie et appareils idéologiques d'état", op. cit., p. 312 (trad. esp.: "Ideología y aparatos ideológicos de estado", op. cit., pp. 122-3.). El dispositivo que produce el efecto de ausencia de exterior lo llama Althusser "mecanismo de reconocimiento especular" (Ibíd., pág. 311 (trad. esp.: pág.122)). Este mecanismo funciona instituyendo la figura de un Sujeto (un Ser, Norma, Modelo, Causa) en nombre del cual se movilizan las interpelaciones. Por mediación de la figura del Sujeto, las interpelaciones consisten en un redoblamiento especular que sujeta a los sujetos $\mathrm{y}$, al mismo tiempo, les garantiza su estatuto de seres que actúan por sí mismos (sujetos). ¿Cómo es posible que se den juntas estas dos operaciones (sujetar y garantizar la iniciativa propia) que en principio parecen incompatibles? Es posible porque el Sujeto actúa como Origen del origen que debe ser el sujeto. Si el sujeto es sujeto, esto es, si obedece por sí mismo, lo es a condición de obedecer al Sujeto, de estar sujeto a él. La paradoja sólo tiene sentido si se entiende que los mandatos del Sujeto se sitúan a dos niveles. A un nivel fundamental, lo que el Sujeto manda por encima de cualquier otra cosa es que el sujeto se reconozca como dotado de iniciativa propia. Y si el sujeto obedece por sí mismo a cualquier otro mandato de nivel secundario, siempre lo hace estando sujeto al mandato fundamental del Sujeto. En consecuencia, los sujetos vivencian sus acciones dentro del "mundo" ideológico establecido alrededor del Sujeto, ya que la desobediencia a los mandatos secundarios, siempre posible "teóricamente", sigue siendo obediencia al mandato fundamental. Y, de una manera o de otra, la posibilidad para ellos de explicar sus acciones en relación a la reproducción de las relaciones de producción deviene tabú. 
Defenderemos, pues, que Lucrecio atribuye a lo imaginario una eficacia propia que explica a través de un automatismo que reproduce el efecto específico. En el caso de Lucrecio, adelantamos, ese efecto específico es la creencia en el alma separable e inmortal y el automatismo, la pasión por imaginarnos mirando.

\section{El temor a morir y el deseo de vivir}

Para poder reconstruir, sin embargo, esa eficacia y ese automatismo específicos es necesario esclarecer los dos sentidos en los que el temor a morir es entendido a lo largo del libro III de De rerum natura y la relación existente entre ellos. PierreFrançois Moreau se ha referido a esos dos significados como el temor a los sufrimientos en el más allá y como el temor a una vida menor o reducida ${ }^{6}$. Permítasenos, respetando la mayor parte de los argumentos de Moreau, aunque seguramente no todos, pensar este segundo temor según una perspectiva más tradicional, aquella de la que habla el propio Epicuro. En efecto, casi al final de la Carta a Herodoto, Epicuro diferencia entre "esperar un mal eterno por las creencias en las leyendas de la mitología" y el "miedo de aquella falta de sensibilidad que nos provoca la muerte" (DL, X, 81)7. Según Epicuro, por tanto, el temor a morir sería o bien temor a los males de ultratumba o bien temor a la ausencia total de sensación. Este último miedo lo podremos distinguir mejor si lo exponemos en su formulación extendida, esto es, si entendemos que el temor a la ausencia de sensibilidad es, más en concreto, el temor que nos provocan las imágenes que fabulan nuestra no existencia individual. Con respecto a los significados que el temor a morir posee en el libro III del De rerum natura, nuestra hipótesis es, entonces, que este miedo a los simulacros que fabulan la disolución del yo es una forma esencial de "deseo desmesurado y perjudicial de vida (mala... uitai tanta cupido)" o de la "constante sed de vida (sitis aequa... uitai)" de las que habla Lucrecio en los versos finales de ese mismo libro.

La reticencia de Moreau a llamar por su nombre a este miedo, a este deseo, es sin duda comprensible. Ya que, como es sabido, según Lucrecio, demostrar una verdad implica que todo error incompatible con ella sea expulsado. De ahí que, de la verdad demostrada por Lucrecio según la cual la muerte no es nada para nosotros, se siga la expulsión de las falsas opiniones sobre las que descansa el temor a la muerte y, al desaparecer estas, se desvanezca el temor. Ahora bien, es obvio que este encadenamiento no funciona del todo mal si el temor a la muerte es un temor a las

\footnotetext{
6 Véase Moreau, P.-F.: Lúcrece. L'âme, París, PUF, 2002, p. 15.

${ }^{7}$ Cito a Epicuro a partir de la numeración interna del libro X de Las vidas de los filósofos ilustres de Diógenes Laercio. Las citas de Lucrecio van señaladas por el número del libro de De rerum natura en el que se encuentra el pasaje, seguido de los números correspondientes a los versos de que se trate. Remito a la bibliografía final para las ediciones y traducciones consultadas.
} 
penas de ultratumba. Si la muerte nada es para nosotros, si no hay más allá, no habrá tampoco penas en el más allá. Pero parece que funciona un tanto peor si lo que se teme son las imágenes que fingen nuestra ausencia. En este segundo caso, en poco nos ayuda saber que la muerte no es nada para nosotros, porque eso, parecería, es lo que verdaderamente tememos, esto es, lo que tememos es que para nosotros la muerte sea la nada.

Por tanto, he aquí nuestro problema. Tenemos que demostrar que la argumentación lucreciana que concluye en que la muerte no es nada para nosotros es también o incluso especialmente relevante para el temor a morir entendido como miedo a las imágenes que nos anuncian una carencia total de sensibilidad. Para ello, tendremos que ser capaces de distinguir con claridad entre la tesis epicúrea de que "la muerte no es nada para nosotros" y la creencia de que "la muerte es para nosotros la nada". A pesar de su parecido, ambas están separadas entre sí por un abismo. El argumento de Lucrecio, como el de Epicuro, va dirigido contra cualquier sustantivación de la nada, cualquier comprensión de la muerte como "nuestra" ausencia.

Partamos, entonces, de dos postulados fundamentales del epicureísmo como son su principio del placer y la concepción del dolor y el placer como movimientos de desequilibrio y reequilibrio de los átomos respectivamente. Ambos están expuestos en el libro II del De rerum natura. El principio del placer aparece como la exigencia de la Naturaleza de que "el cuerpo se aleje del dolor, y que la mente, rescatada del cuidado y del miedo, goce de un sentimiento agradable" (II, 17-19). Recordemos, de cualquier manera, el modo en que Epicuro expone ese principio en la Carta a Meneceo: "Porque tenemos necesidad de placer en el momento en el que, por no estar presente el placer, sentimos dolor. Pero cuando no sentimos dolor, ya no tenemos necesidad del placer" (DL, X, 128).

La tesis que concibe la enfermedad y el dolor como movimientos aparece en ese mismo libro II, pero cientos de versos más adelante. Allí, Lucrecio señala que el dolor se produce "cuando los átomos de la materia, trastornados por alguna fuerza en las entrañas vivas y en los miembros, se tambalean en el interior de sus sedes" (II, 963-965). El placer regresa, entonces, en el momento en que los átomos recuperan su movimiento de equilibrio.

Combinando ambas tesis, hemos de entender, pues, que el dolor, ese tambalearse de los átomos, genera en nosotros un deseo o una necesidad de placer. El dolor hace entrar en acción la exigencia de la naturaleza de alejarlo del cuerpo. Esa exigencia se traduce en que el desequilibrio del dolor es resistido por el propio cuerpo (como conjunto): así cuando recibimos un golpe "los demás movimientos vitales... reconducen los elementos a su camino habitual, desbaratan por así decir el movimiento de la muerte que se adueñaba del cuerpo" (II, 955-958). Traduciendo la demanda de resistencia que impone la naturaleza a términos teóricos, podemos decir que la trabazón (textura) del cuerpo ha de poseer una cierta estabilidad, cohe- 
sión o consistencia (nexus), de otro modo cualquier pequeño choque la haría desmoronarse - cosa que la experiencia desmiente- y no existirían cuerpos de ningún tipo. Como describe Lucrecio en I, 238-247:

Una misma fuerza y una misma causa acabaría indistintamente con todas las cosas si a cada una no la sostuviera una materia eterna, trabada con mayor o menor consistencia (inter se nexus minus aut magis indupedita): el simple contacto sería, en efecto, causa suficiente de muerte, puesto que no habría partículas de cuerpo perenne, cuya trama requiriera, para ser disuelta, una fuerza especial. Pero ahora, siendo de diferentes tipos las conexiones que ensamblan los elementos y eterna su materia, las cosas subsisten incólumes hasta que chocan con una fuerza lo bastante violenta para deshacer su trabazón (textura).

En consecuencia, los desequilibrios producidos por los choques o por las continuas pérdidas de átomos (IV, 858-876), mientras se mantengan dentro de cierto umbral, que es el umbral de la vida ("el nudo de la vida que liga el ánima con el cuerpo" II, 950), son contrarrestados por los propios movimientos vitales del cuerpo. A estos movimientos de resistencia los podemos llamar "deseos de placer" (por ejemplo, el hambre o la sed, véase IV, 858-876, o el deseo sexual, véase IV, 10411048), pero igualmente, "deseos de vida". Siendo el dolor la antesala de la muerte (II, 960), desear el placer es desear la vida. El deseo en Lucrecio es, entonces, el movimiento que el cuerpo necesariamente realiza resistiéndose a los desequilibrios de movimiento que los choques con otros cuerpos o la pérdida continua de elementos producen en el entrelazamiento de sus átomos. O, dicho de otro modo: el deseo es el índice de la consistencia del cuerpo. Por ello, el deseo lucreciano es siempre deseo de vivir.

Es un principio fundamental del epicureísmo, por lo demás, que estos deseos de vivir pueden tener exceso y pueden ser perjudiciales. El exceso y el perjuicio provienen de que los deseos de placer no disciernen entre placeres perjudiciales y beneficiosos, ni tampoco entre dolores de ambos tipos. La distinción entre placeres o dolores de uno u otro tipo requiere, como dice Epicuro, del "cálculo y la atención a los beneficios y los inconvenientes" (DL, X, 130). Espontáneamente, el deseo de vida anhela placer sin calcular el dolor que a ese placer le pueda seguir y resiste al dolor aunque vaya a tener como consecuencia un mayor placer. Cuando, "en momentos de dudas y peligros" (III, 55), a causa del temor a la muerte, se oscurece el ánimo, el cálculo y la atención se desbaratan. Y entonces el deseo de vivir actúa de forma tan desmedida que, como afirma Lucrecio al principio del libro III, llega incluso a convertirse en su contrario, en odio a la vida.

Tenemos, entonces, aquí una primera aproximación entre el miedo a morir y el "deseo de vida desmesurado y perjudicial". Sin embargo, para ser identificado con el temor a morir como miedo a los simulacros de "nuestra" ausencia, el deseo de 
vida desmesurado necesita ser complementado con una perspectiva de totalidad de la que hasta ahora no hemos podido apuntar nada. En efecto, aunque, la respuesta del cuerpo ante todo dolor es una respuesta de conjunto, los deseos de placer o de vida, como el hambre, la sed, el deseo sexual o el sueño, son deseos siempre parciales, que remiten a unos dolores, a un tambalearse o una irritación de los átomos que son particulares, específicos de partes del cuerpo. No son portadores, en definitiva, de la amenaza total que asoma en el temor a morir o en el deseo desmesurado de vida, con todos sus efectos. La visión totalizante de uno mismo, de nuestra vida o de nuestra muerte, solo puede explicarse a partir, ahora sí, de la teoría de lo imaginario que Lucrecio desarrolla en el libro IV.

\section{EI dolor, la muerte, la anticipación}

Ahora bien, para abordar con acierto la teoría lucreciana de lo imaginario, en primer lugar hemos que tener en cuenta dos cuestiones importantes. Antes que nada debemos esclarecer el modo en que Lucrecio conecta dolor y muerte. Y después tenemos que entender que la teoría de lo imaginario está ligada en Lucrecio, al igual que en Spinoza ${ }^{8}$ y Althusser ${ }^{9}$, no sólo a una teoría del conocimiento, sino, principalmente, a una teoría de la acción. En ambas cuestiones el escollo más peligroso que es necesario evitar se llama "finalismo".

Veamos, entonces, la relación entre dolor y muerte. En II, 960, como hemos dicho, Lucrecio se refiere al dolor como "umbral de la muerte (leti... limine)"10. El problema con esta expresión es que puede llevar a pensar la resistencia al dolor como una forma de anticipación de la muerte, con la recaída en el finalismo que semejante lectura acarrearía. Por ello, si hemos de evitar caer en el finalismo, el dolor como umbral de la muerte y el deseo de placer como deseo de vida han de entenderse en tanto que resistirse al dolor es índice de la consistencia del cuerpo, pero no como si esa resistencia anticipara la muerte, ya sea "por naturaleza" en sentido aristotélico, porque sea su "destino" en sentido estoico o por otra razón. Las reacciones de los movimientos vitales de las que habla Lucrecio son siempre contra un trastorno parcial y a la medida del mismo. Es cierto que reaccionando contra

\footnotetext{
8 Véase el modo en que Spinoza define el amor y el odio en Ética III, prop. 28.

9 Véase la identificación que Althusser realiza entre ideología y conducta o comportamiento en Althusser, L.: Pour Marx, La Découverte, París, 1996, pp. 149 y 242 (trad. esp. La revolución teórica de Marx, trad. M. Harnecker, Siglo XXI, México D.F., 1999, pp. 123 y 195) y en "Idéologie et appareils idéologiques d'état", op. cit., pp. 301 y 311 (trad. esp.: "Ideología y aparatos ideológicos de estado", op. cit., pp. 109 y 122). Y véase también Montag, W.: "The soul is the prison of the body: Althusser and Foucault, 1970-1975", op. cit.

10 En III, 67, Lucrecio afirma igualmente que el desprecio y la pobreza parecen "demoras ante las puertas de la muerte".
} 
el trastorno parcial, el cuerpo actúa también contra la disolución total, de ahí que podamos hablar de "deseos de vida", pero no actúa por anticipación del resultado, sino a causa de su naturaleza trabada. Esa es la razón por la que hemos de suponer que la reacción expresa contra la muerte, el temor a morir, sólo puede ser una reacción que se produce en el ánimo, esto es, allí donde se puede atender a una imagen de totalidad que inicie una acción corporal.

La segunda cuestión, por su parte, sólo la podemos abordar si nos ocupamos con algún detalle de la teoría de lo imaginario que Lucrecio expone en el libro IV. En efecto, lo que está en juego de manera fundamental en esta teoría es el modo en que el ánimo prevé lo que va a hacer el cuerpo, esto es, qué cosas recibidas mueven al ánimo (IV, 722). Y la explicación dada por Lucrecio es que el ánimo no puede actuar sobre el ánima si no posee una imagen del cuerpo en movimiento. Esa imagen no proviene de los simulacros que recibimos por los sentidos, porque no es una imagen de presencia, sino anticipatoria. Ha de provenir, por tanto, de los simulacros más finos que sólo el ánimo recibe.

Sostengo que vienen primero simulacros de movimiento a nuestro ánimo y lo excitan, como antes explicamos. De ahí nace la voluntad de moverse; pues nadie empieza a hacer nada antes de haber previsto en su ánimo lo que quiere hacer. Y de la acción que prevé realizar tiene presente la imagen. Luego el ánimo, excitado por el deseo de ponerse a caminar, hiere la fuerza del ánima que se encuentra diseminada por todo el cuerpo, en órganos y miembros, y le es fácil hacerlo, dada la íntima unión de los dos. A su vez el ánima hiere el cuerpo, y así poco a poco es empujada la masa entera y entra en movimiento. (IV, 881-891)

El problema para Lucrecio consiste, entonces, en determinar cómo se unen los deseos de nuestro ánimo ${ }^{11}$ con unas imágenes u otras, convirtiéndolas en intencionales. Es sabido que los deseos del ánimo, que son igualmente deseos de placer, deseos de reequilibrar un movimiento interno trastornado, no poseen ni producen por sí mismos una imagen de cómo mover el cuerpo entero para restituir ese equilibrio perdido. Esa imagen la encuentra el ánimo entre los muchos simulacros que le llegan expresamente a él por los intersticios del cuerpo. De qué depende que el ánimo acierte o no con la imagen adecuada no nos lo dice Lucrecio. Podemos entender que esa imagen es una forma de prólepsis y que resulta, por tanto, del proceso de formación específico de estas, que incluye momentos de mejor o peor confirmación. Lo que parece estar claro de cualquier manera es que esa imagen ha de ser una

11 Seguimos aquí los análisis y sus conclusiones que sobre este asunto realiza Alain Gigandet. Como el estudioso francés señala: "Ce sont donc, semble-t-il, les désirs dominants du sujet, passions, phobies, qui commandent la projection de l'spirit vers le flux des simulacres disponilbles, l'attention sélective qui lui fait retenir les images attendues" (Gigandet, A.: Fama deum. Lúcrece et les raisons du mythe, París, Vrin, 1998, p. 256). 
imagen del cuerpo en movimiento. Y eso significa que el ánimo sólo puede prever acciones si es afectado por imágenes de nuestro propio cuerpo en movimiento. En definitiva, para que pueda haber previsión y, por tanto, acción, entre los múltiples simulacros que mueven a nuestro ánimo, han de encontrarse necesariamente también simulacros de nuestro propio cuerpo en acción.

\section{La imposibilidad de representar la muerte}

Hasta aquí es hasta donde expresamente nos lleva Lucrecio. El camino que falta para reconstruir el automatismo que produce la creencia en el alma separable lo tenemos que reconstruir nosotros solos. Ya hemos adelantado que, en sentido estricto, nosotros no tenemos miedo a la muerte. Tenemos miedo a los simulacros que, sin representarla, la fingen. De esos simulacros "deducimos el sentido (consequitur sensus)... de lo que ha de seguir" (I, 459-461), sin que, sin embargo, lo que ha de seguir aparezca de manera alguna. Las imágenes de nuestro cuerpo dolorido, las imágenes de personas difuntas, la imagen del abismo, de la noche, de la oscuridad y del frío... fabulan la muerte sin representarla. Ese tipo de imágenes, que llegan a nosotros en los sueños, que pueden ser requeridas incluso para anticipar la acción en el cálculo de placeres y que son reconocidas y usadas socialmente a través del imaginario colectivo que constituyen los mitos, inquietan al ánimo, es decir, lo trastornan, lo sacan de su sitio, pero no representan la muerte en sentido estricto.

Y nuestra hipótesis es que la causa principal que explica por qué los simulacros que fabulan la muerte inquietan al ánimo es precisamente el hecho de que lo que fingen, la muerte, no sólo no lo representan, sino que es en sí mismo irrepresentable. Entendemos, así, que la tesis fundamental del epicureísmo que Lucrecio demuestra detenidamente en el Libro III, esto es, que la muerte no es nada para nosotros significa sobre todo que no podemos representar nuestra muerte. Esta imposibilidad de representar la muerte es nuestra herida. No puede haber un simulacro de la muerte. Las imágenes que fingen la muerte propia, fabulan algo irrepresentable.

La escena en la que incluso aquellos que descreen de una vida futura se imaginan vivos junto a su cadáver es un ejemplo donde la imposibilidad de representar la muerte se ilustra perfectamente.

En efecto, cuando en vida se imagina que su cadáver ha de ser desgarrado por las aves y las fieras, se compadece de sí mismo. Porque no se ve distinto de aquél, ni se retira bastante de su cuerpo caído, y se figura que él es todavía este cuerpo y, de pie a su lado, le presta su propio sentimiento. (III, 879-883) 
Así, sólo podemos imaginar nuestro cadáver, sólo podemos referirnos a nuestra muerte, incluso si no nos apoyamos en ninguna leyenda de ultratumba, a condición de figurarnos a nosotros mismo mirando y siendo mirados, compadeciendo y sufriendo, esto es, a condición de imaginarnos vivos. El sinsentido puede adquirir otras formas. Aparece, por ejemplo, cuando lo que imaginamos no es tanto nuestro cadáver, como la total falta de sensibilidad producida por la muerte, que diría Epicuro. De forma similar, frente a la alteridad real de nuestra ausencia, dado que no podemos representarla, nos imaginamos mirando sus "ciegas tinieblas".

El imaginarnos vivos ante las ficciones de la muerte no es, entonces, sino la reacción ante la imposibilidad de representarla. Ya que representar nuestra muerte, si eso fuera posible, implicaría fantasear nuestra ausencia sin nadie presente ante su simulacro, imaginar nuestra ausencia como un reflejo especular que nadie está mirando. Pero no podemos imaginar una imagen que nadie mira. Nuestro imaginario es limitado, es finito. Aunque puede sonar como un trabalenguas, hay que decir que imaginar supone siempre imaginarnos mirando la imagen imaginada. Una imagen que nadie mira es algo irrepresentable. Ahora bien, si no podemos imaginar una imagen que nadie mira, sea la que sea, es precisamente porque imaginarla sería una manera de representar la muerte. La imposibilidad de imaginar una imagen que nadie mira y la imposibilidad de representar la muerte son una y la misma imposibilidad $^{12}$. Y, por tanto, la reacción ante ambas imposibilidades es la misma: la necesidad de imaginarnos mirando.

Partiendo de la tesis de Lucrecio de que la acción de imaginar se integra dentro del proceso de la acción corporal completa, podemos intentar exponer el modo en que la imposibilidad de representar nuestra muerte opera en la imaginación. La imagen anticipatoria nos mueve a actuar y es, por ello, una componente del deseo. La anticipación de nuestro comportamiento se produce entonces siempre entre las dos vertientes, por decirlo así, de la acción. Surge entre la acción de representar y la imagen de la conducta anticipada. Esto es así porque el ánimo presta atención de manera compulsiva al simulacro de nuestra acción de mirar de modo que éste acompaña siempre a todo otro simulacro que el ánimo seleccione. O dicho de otra forma, por medio de esta atención compulsiva, el ánimo "constituye" siempre la acción de representar como la imagen de una acción particular: como nuestra imagen mirando; transforma la acción de representar en una representación que nos muestra mirando. Esa atención compulsiva es el modo en que el ánimo responde al límite de

12 Como me recuerda Alain Gigandet en comunicación personal, cabe igualmente argumentar la irrepresentabilidad de la propia muerte desde la canónica epicúrea. Dado que una prolepsis se constituye a partir de experiencias repetidas y que de mi muerte no tengo ni puedo tener experiencia alguna, es imposible construir una prolepsis de ella. Toda representación que pueda hacer de mi muerte es, en consecuencia, falsa y se produce al unir a los simulacros que anuncian mi fin la imagen imposible de mi mismo como testigo de mi defunción. 
la imaginación, a su propia incapacidad para imaginar una imagen que nadie mira. Y la transformación que produce dota de continuidad temporal a la imagen anticipatoria: el presente y el futuro son reunidos en la misma imagen. Pero, al excluir la diferencia real entre las dos acciones, al borrar la materialidad de lo imaginario, al fantasear la acción de imaginar, también provoca la ficción finalista, aquella que hace parecer que lo imaginado futuro nos atrae o repugna (a nosotros identificados con nuestra imagen mirando) como causa final, en lugar de mover nuestro ánimo como causa eficiente.

Ahora bien, al imaginar las ficciones de la muerte ocurre algo específico. Sucede que la continuidad lograda al transformar en imagen la acción de imaginar es una continuidad extremadamente precaria. La imagen que nos muestra mirando y la imagen que fabula la ausencia de toda sensibilidad se continúan como en toda anticipación en la línea del ahora y el después, pero al mismo tiempo entre ellas se establece una incompatibilidad que nunca puede ser enteramente disimulada. Son la imagen de la vida actual y la imagen que anuncia la muerte futura, la imagen del deseo y la imagen de la que se sigue su total ausencia: el abismo que separa las dos imágenes es irrestañable. De ahí la inquietud de la mente, su trastorno, esa herida que nunca cicatriza. Imaginarnos mirando la ficción de nuestra muerte es una reacción que tiende un puente ficticio de continuidad entre la imagen del deseo y la que finge su ausencia, pero es un puente construido sobre basamentos demasiado frágiles para la altura sobre la que se eleva.

\section{La obsesión por imaginarnos mirando}

Nos es imposible representar nuestra muerte y si imaginamos simulacros que la fabulan, necesariamente van acompañados de imágenes en las que nosotros aparecemos mirando. Ahora bien, la dinámica espontánea no se detiene ahí. La precariedad de la unión entre las imágenes que fingen la muerte y las que nos muestran mirando adopta una forma de bucle. El ánimo queda "engarzado" en un ciclo iterativo que reproduce la inquietud del abismo y la esperanza de la continuidad. En efecto, el ánimo reacciona ante las imágenes que anuncian la muerte irrepresentable prestando atención a una imagen de nosotros mismos como testigos de esa ficción. Pero, al reaccionar así, la primera imagen, la que provoca la inquietud, no desaparece. En lugar de conducir a expulsar la causa de la inquietud, la reacción lleva a retenerla como objeto de la mirada imaginada. Y, a su vez, retener la imagen que fabula nuestra muerte provoca que la reacción continúe, esto es, hace que la mente siga prestando atención al simulacro que nos muestra expectantes. $Y$ así indefinidamente: la imagen que finge nuestra muerte mueve al ánimo a anticipar la imagen que nos figura mirando; pero, la acción imaginada de mirar arrastra consigo la 
necesidad de que haya algo que sea mirado. Lo mirado entonces es la ficción de la muerte que, de este modo, es retenida en lugar de expulsada y desencadena un bucle de inquietud y esperanza que se reproduce por sí mismo. El efecto que resulta de este ciclo recurrente es esa pulsión inútil por huir de uno mismo a la que Lucrecio se refiere en varios momentos de la última parte del libro III, pero con especial énfasis en los versos 1068-1069: "es así como cada uno huye de sí mismo, pero como esa huida es sin duda imposible, queda a su pesar encadenado a este sí mismo y lo odia" 13 .

Imaginarnos mirando las imágenes de cosas que fabulan nuestra ausencia (esas cosas que se parecen a las "que en la oscuridad temen los niños e imaginan inminentes" (III, 89-90)) sujeta esas imágenes a un mecanismo iterativo que "enturbia en sus mismas raíces la vida de los hombres, ensombreciéndolo todo con el negror de la muerte y sin dejarnos un solo gozo límpido y puro" (III, 37-40). Esa pulsión inútil por huir de uno mismo que en su mismo escapar reproduce aquello de lo que huye tiene la misma forma iterativa que los mitos atribuyen a los castigos del "profundo Aqueronte". Es, digamos, como "echar agua en un vaso agujereado" (III, 1009).

Disponemos ahora ya entonces de todos los elementos para poder explicar cómo la creencia en el alma separable e inmortal se produce por medio de un mecanismo relativamente independiente de los cultos religiosos o de las mitologías que históricamente la han alentado y explotado. El alma separable e inmortal tiene su base material primera en la transformación de la acción de imaginar en una imagen que nos muestra mirando. Esa base primera se produce, se constituye como reacción ante la inquietud que al ánimo le ocasiona toparse con sus propios límites, con la incapacidad para imaginar la imagen que nadie mira. Pero, cuando el ánimo atiende entonces a las ficciones de "la imagen que nadie mira", esto es, de la muerte, la reacción equilibradora reintroduce la inquietud y queda engarzada en un ciclo iterativo de imágenes de nuestra acción de mirar y de las ficciones de la muerte miradas, en un juego de reenvíos infinito en el que ambos extremos se movilizan incesantemente entre sí. En este segundo momento, la imagen que nos muestra mirando queda atrapada en un automatismo. La dinámica casi independiente de este automatismo combinada con la exclusión de la acción real de imaginar que resulta de su constitución como imagen hace que el simulacro que nos representa mirando se presente a sí mismo como un fantasma separable de toda corporalidad. En fin, la estructura formal, el mecanismo que produce el efecto específico de la creencia en el alma separable e inmortal es la imagen de nuestro mirar producida como doble reacción: primero, ante la imposibilidad de representar la muerte o la imagen que nadie mira y, segundo, como reacción que se suma a la primera, constituyendo un ciclo iterativo al confrontarse con las imágenes que fingen nuestra ausencia.

13 Véase también III, 957 y 1082-3. 
Desde esta perspectiva, el temor a morir sólo puede pensarse como la misma atención compulsiva del simulacro de nuestro mirar atrapada en la dinámica circular del ciclo iterativo, ciclo del que los mitos que relatan los horrores del inframundo son tanto efecto como causa. Y lo que hace que el miedo a la muerte sea una forma de "mala ansía de vida" 14 es, por tanto, el carácter automático de ese mismo ciclo. Ahora bien, el miedo a morir no es una forma cualquiera de deseo desmesurado. Es la forma gracias a la cual es posible descubrir el principio que rige ese deseo. Es la forma por la que descubrimos que la pasión primaria es precisamente la obsesión por imaginarnos mirando por la que se produce la creencia en un alma separable e inmortal.

El descubrimiento y la explicación de la obsesión por imaginarnos mirando asienta el conocimiento de que la muerte no es nada para nosotros al establecer que entre el temor a morir y la creencia en la inmortalidad existe en todos los casos (tanto si el temor es a los castigos de ultratumba como si es a la imagen de nuestra ausencia) una conexión necesaria.

\section{Referencias bibliográficas}

Althusser, L.: Pour Marx, París, La Découverte, 1996 (trad. esp. La revolución teórica de Marx, trad. M. Harnecker, México D.F., Siglo XXI, 1999).

AlthUSSER, L.: "Idéologie et appareils idéologiques d'état", in Sur la reproduction, París, PUF, 1995 (trad. esp.: "Ideología y aparatos ideológicos de estado", en Posiciones, trad. A. Roies, Barcelona, Anagrama, 1977).

Althusser, L.: "Éléments d'autocritique", Solitude de Machiavel, París, PUF, 1998 (trad. esp.: Elementos de autocrítica, trad. M. Barroso, Barcelona, Laia, 1975). Bertrand, M.: Spinoza et l'imaginaire, París, PUF, 1983.

Bove, L.: La stratégie du conatus. Affirmation et resistance chez Spinoza, París, Vrin, 1996 (trad. esp.: La estrategia del conatus. Afirmación y resistencia en Spinoza, trad. G. Sanz Espinar, Ciempozuelos, Tierradenadie ediciones, 2009). CASTORIADis, C.: "El descubrimiento de la imaginación", en Los dominios del hombre, trad. A. L. Bixio, Barcelona, Gedisa, 1998.

EPICURO, Obras, trad. M. Juffresa, Madrid, Tecnos, 2005.

EPICURUs, The Epicurus Reader. Selected Writings and Testimonia, trad. B. Inwood and L.P. Gerson, Indianapolis, Hackett, 1994.

García Gual, C.: Epicuro, Madrid, Alianza Editorial, 1988.

Gigandet, A.: Fama deum. Lúcrece et les raisons du mythe, París, Vrin, 1998.

\footnotetext{
14 Como traduce Agustín García Calvo el "mala... uitai tanta cupido", véase, Lucrecio, De rerum natura / De la realidad, edición crítica y versión rítmica de A. García Calvo, Lucina, Zamora, 1997, p. 286.
} 
HeIDEGGER, M.: Kant y el problema de la metafisica, trad. G. Ibscher Roth, México D.F., FCE, 1986.

LuCRECIO, De rerum natura / De la naturaleza, trad. E. Valentí Fiol, Barcelona, Bosch, 1993.

LuCRECIO, De rerum natura / De la realidad, edición crítica y versión rítmica de A. García Calvo, Zamora, Lucina, 1997.

LuCRETIUS, On the Nature of Things, trad. M. Ferguson Smith, Indianapolis, Hackett, 2001.

Montag, W.: "The soul is the prison of the body: Althusser and Foucault, 19701975", Yale French Studies, 88, 1995. (trad. esp.: "El alma es la prisión del cuerpo: Althusser y Foucault, 1970-1975”, trad. A. Sainz Pezonaga, Youkali, 8, 2009).

Moreau, P.-F.: Lúcrece. L’âme, París, PUF, 2002.

SAinz PezonagA, A.: "El deseo activo de amar (afecto y materialismo en Spinoza)", Youkali, 3, mayo 2007.

SPINOZA, B.: Ética demostrada según el orden geométrico, trad. A. Domínguez, Madrid, Trotta, 2005.

Aurelio Sainz Pezonaga

IES Santiago Grisolía de Cuenca asainzpezonaga@gmail.com 